\title{
A RETROSPECTIVE STUDY ON CARDIAC DISEASE IN PREGNANCY
}

KEY WORDS:

\section{Dr. Mounika Edupuganti}

\section{Dr. Panthagani} Vineela*

\section{Introduction}

Cardiac disease in pregnancy is one of the common, indirect obstetric causes of maternal mortality reported incidence varying between 0.5 and $5.9 \%$ worldwide. The rise in maternal mortality has been attributed to increasing numbers of women at advanced maternal age undertaking pregnancy, comorbid pre-existing conditions such as diabetes mellitus and hypertension and the growing number of women with congenital heart disease surviving to childbearing. Valvular heart disease is present in $80 \%$ of patients with heart disease during pregnancy in developing countries with rheumatic fever as the most common etiology and the mitral valve being the most commonly affected valve, but is uncommon in developed countries. Heart failure complicating rheumatic heart disease in pregnancy has been described in $22 \%$ women presenting to clinics in India and few African countries.

\section{Methods}

A retrospective analysis of all patients admitted with cardiac disease over two years period was performed. All patient data (inpatient and out-patient information) at IALCH is recorded onto a clinical software. Information retrieved from this database included demographic details, clinical management, surgery performed in prepregnancy period and during pregnancy, and data on maternal and fetal outcomes.

The usual policy at IALCH is that cardiac patients are admitted on the first visit for a complete clinical assessment. A detailed history is obtained and the patients disability graded according to the New York Heart Association classification. Blood investigations included a full blood count, serum renal function tests, testing for viral markers ( $\mathrm{HIV}, \mathrm{HBsAg}, \mathrm{HCV}$ ), urine analysis for detecting infections and specific tests included ECG, USG and echocardiogram. A cardiologist, together with an obstetrician interested in medical complications of pregnancy assessed all patients and reviewed treatment regimens.

Patients with prosthetic metallic valves received heparin in the first trimester and this was converted to warfarin at 13 weeks gestational age and then reconverted to heparin at 36 weeks gestational age.

Following initial assessment, patients who were in NYHA functional class I and II were managed as outpatients and followed up weekly. Those who were in NYHA class III and IV were hospitalised mainly due to poor social circumstances and the fact that most were referred from distant areas of the province.

If antenatal care was uneventful, decisions on mode of delivery and review by anaesthesiologists was taken at approximately 34 weeks gestation. Vaginal delivery with elective induction is reasonable so that labour and delivery are attended by a scheduled, experienced team. Vaginal delivery with epidural analgesia for pain relief was the |www.worldwidejournals.com

principle guiding the decision on mode of delivery. Caesarean section was performed if vaginal delivery was contraindicated for obstetric reasons. All primigravidae had computerised tomographic pelvimetry to assess cephalopelvic disproportion, as trial of labour was not allowed in cardiac patients with an inadequate pelvis.

Maternal outcome was analysed using the following criteria: deterioration in NYHA functional class, cardiac complications, noncardiac complications, cardiac interventions during pregnancy and mode of delivery. Neonatal outcome was analysed using the following criteria; time of delivery, birth weight, stillbirth, congenital abnormalities and congenital pneumonia.

\section{Study}

This study was a retrospective review of patient charts with cardiac disease in pregnancy in a developing country country like India.

The patients were classified based on NYHA classification. Ninety-five patients were evaluated; the majority were in the age group 21-25years. Rheumatic heart disease was the commonest aetiology, eight women required balloon mitral valvuloplasty and one had a valve replacement at 32 weeks gestation.

There were no maternal deaths but morbidity was high, 13 patients were admitted in cardiac failure, nine had atrial fibrillation and three required intensive-care management. There were 86 live births of the 97 deliveries.

Cardiac disease in pregnancy is associated with high maternal morbidity and adverse foetal outcomes, this was related to late presentation and problems with anticoagulation. Clinical assessment remains a key factor in timeous referral and appropriate investigations.

\section{TABLE 1. DEMOGRAPHIC DATA O F A LU PATIENTS}

Characteristics

Age (years)

$15-20$

21-25

26-30

$31-40$

$>40$

Parity

Primigravida

Pl-3

$\geq \mathrm{P} 4$

Previous miscarriage

Gestational age at admission

1st trimester

2nd trimester

3rd trimester

Gestational age at delivery (weeks)

$<28$

28-32

34-36
No of patients

12

36

24

18

5

38

53

4

11

6

31

58

2

7 


\begin{tabular}{|lc|}
\hline Term & 60 \\
NYHA class & \\
I & 38 \\
II & 33 \\
III & 16 \\
IV & 8 \\
NYHA 5 New York Heart Association. & \\
\hline
\end{tabular}

\section{Results}

Ninety-five patients with cardiac disease were seen during the study period of two years in katuri medical college and hospital and few infertility centres in and around Guntur.The demographic data are shown in Table 1. Cardiac disease was detected for the first time during pregnancy in 23 cases, 18 of which had RHD. There was one case of twin pregnancy; 72 patients were under 30 years old and most were multiparous . The majority presented for antenatal care in the third trimester and six delivered at $\leq 32$ weeks gestation.

The anatomical and pathological valve lesion in all 95 patients is shown in Table 2. Rheumatic heart disease was the underlying pathological condition in $81 \%$ of cases. There were 71 in functional class (NYHA) I-II and 24 in class III-IV. Congenital heart disease accounted for $9.5 \%$ of cases. In addition to cardiac disease, 19 patients had associated medical conditions, hypertension was the most prevalent, followed by asthma, diabetes and epilepsy. The remaining seven had chest infections and urinary tract infections.

\section{TABLE 2.CLINICAL SPECTRUM OF CARDIAC DISEASE}

\section{Cardiac lesion}

Rheumatic heart disease

No of patients
77
22
17
11
1
1
5
20
9
2
5
1
1
5

Mitral stenosis

Mixed mitral valve

Mitral regurgitation

Aortic regurgitation

Aortic stenosis

Multiple valve lesion

Metallic valve replacement

Congenital heart disease

Atrial septal defect

Ventricular septal defect

Patent ductus arteriosus

Tetralogy of Fallot

Myocardial/other

5

Echocardiograms were performed in all patients. The ejection fraction was normal in all except three with cardiomyopathy. The mitral valve area ranged from $0.3-2.8 \mathrm{~cm} 2$. The severity of mitral stenosis was graded according to mitral valve area, EchoDoppler studies identified seven patients as having moderately severe to critical mitral stenosis (mitral valve area $0.8-1.2 \mathrm{~cm} 2$ ), changing the clinicians diagnosis of mixed mitral valve disease.

Although there were no maternal deaths during the study period, a significant number of cardiac and non-cardiac complications were encountered in 32 patients (Table 3 ). Cardiac complications occurred in 30 patients and were mainly related to rhythm disturbances and heart failure. Outcomes are discussed under the following categories: rheumatic heart disease, congenital heart disease and myocardial disease.

\section{TABLE 3. COMPLICATIONS ASSOCIATED WITH CARDIAC} DISEASE IN PREGNANCY

\section{Complication}

No of patients

\section{Cardiac}

Atrial fibrillation

Heart failure

Intensive care admission

Infective endocarditis

3

Pulmonary embolism

Supraventricular tachycardia

2

1

3

Hypercoagulation

Severe hypertension

\begin{tabular}{|lc|}
\hline Wound haematoma & 2 \\
Cerebral infarct & 1 \\
Non-cardiac & 4 \\
Puerperal sepsis & 1 \\
Broad ligament haematoma & 5 \\
Postpartum haemorrhage & 13 \\
Anaemia $(\mathrm{Hb}<9 \mathrm{~g} / \mathrm{dl})$ & 15 \\
Thrombocytopenia (Plt < 1503 109/1) & \\
\hline
\end{tabular}

Study group with Rheumatic heart disease

Rheumatic valve disease: Of the 77 patients in this group, 26 had a corrective surgical measure performed prior to pregnancy and 18 had newly diagnosed cardiac disease. The remainder were known to have valvular disease.

Metallic valve replacement:Twenty patients had metallic valve replacement prior to pregnancy (Table 2). All but six had their first visit in the second/third trimester and therefore did not receive heparin in the first trimester. One had defaulted on follow up with her physician and was not on any anticoagulants. Two were symptomatic (NYHA III-IV); one presented in heart failure from a clotted valve and the other had a leaking prosthesis. The patient who presented in cardiac failure at 32 weeks, secondary to a thrombosed prosthetic valve, required an emergency valve replacement. During the procedure, she went into labour and delivered a stillborn foetus.

Maternal complications were noted in 10 patients: two had atrial fibrillation and wound haematoma, two had atrial fibrillation antenatally and postpartum haemorrhage later, two had congestive cardiac failure, two had postpartum haemorrhage, and in another two, there were problems related to poorly controlled anticoagulation. Five patients delivered prematurely at gestations of $\leq 36$ weeks, three had an elective caesarean section, one had an emergency caesarean section, and one was delivered by forceps. Five patients had adverse fetal outcomes, one had a miscarriage, one had a neonatal death associated with a congenital anomaly (gastroschisis), three had stillbirths (two of whom had gross congenital anomalies). Another three babies had low birth weights $(<2 \mathrm{~kg})$.

Stenotic valve lesions: There were 22 patients with mitral stenosis and one with aortic stenosis; 10 patients with mitral stenosis were diagnosed for the first time during pregnancy and 11 were in NYHA class III-IV. Four patients had undergone balloon mitral valvuloplasty (BMV) prior to pregnancy. Eight patients required BMV during pregnancy, in three of these it was performed for restenosis following BMV. Five patients presented in cardiac failure and another five had atrial fibrillation. One of the patients in congestive cardiac failure was at 31 weeks of gestation. She had a tight pliable mitral stenosis (valve area $0.8 \mathrm{~cm} 2$ ) with pulmonary hypertension. She had a scoliosis and was in respiratory acidosis, necessitating ventilation. She also had pre-eclampsia with foetal compromise and thrombocytopaenia. She had an emergency caesarean section and delivered a 1.54-kg infant. There were five others with low birth weights $(2-2.4 \mathrm{~kg})$. The patient who had severe aortic stenosis and mitral stenosis delivered a low-birth weight infant at term.

Of the 22 patients with mitral stenosis, 14 delivered by caesarean section, (five had emergency caesarean section) and eight had vaginal deliveries. One of the patients who had balloon mitral valvuloplasty in pregnancy had spontaneous rupture of membranes following the procedure and delivered a live infant. One patient had an intrauterine death following an amniocentesis done on the basis of advanced maternal age.

Mixed mitral valve disease: Of the 17 (22\%) patients with mixed mitral valve disease, 13 were known to have valvular disease and four were newly diagnosed during the pregnancy. Two patients had undergone balloon mitral 
valvuloplasty prior to pregnancy for tight mitral stenosis. Four patients were in NYHA class III-IV. Three of the four newly diagnosed patients developed complications; congestive cardiac failure (one), severe hypertension (one) and puerperal sepsis (one). All in this group responded to medical treatment and surgical intervention was not required.

A further four patients developed complications as follows: congestive cardiac failure following on infective endocarditis (one), atrial fibrillation (one), wound haematoma (one) and cerebrovascular accident (one). The patient who had a cerebrovascular accident was a primigravida who had a mixed lesion with predominant stenosis (mitral valve area: 1.2 $\mathrm{cm} 2$ ). She had an elective caesarean section at 37 weeks for oligohydramnios with a borderline pelvis and delivered a live $2.5-\mathrm{kg}$ infant. On day 28 , she presented with aphasia and a right hemiplegia and CT scan revealed an infarct in the left middle cerebral artery territory; an echocardiogram showed no thrombi.

Ten patients delivered at term and the remainder delivered at 29-36 weeks gestation. Twelve were delivered by elective caesarean section (three had emergency caesarean section) and there were five vaginal deliveries. There was one stillbirth in this group; the patient presented in advanced preterm labour at 29 weeks with an intrauterine death.

Regurgitant valvular lesions: This group of 17 patients constituted those who had pure mitral regurgitation, mitral regurgitation with aortic regurgitation (n 54 ) and the other lesions were aortic regurgitation ( $n 51)$ and mitral regurgitation with tricuspid regurgitation. Two were NYHA class III-IV and responded to medical therapy. One had congestive cardiac failure and a second had supraventricular tachycardia with infective endocarditis in the antenatal period. Of the 17 in this group, three patients were newly diagnosed. Eight patients were delivered elective caesarean section, one by emergency caesarean section, and 10 were delivered vaginally.

One patient who had supraventricular tachycardia was noted to have intrauterine growth restriction at 36 weeks gestation and delivered a live 2.02-kg infant with a good Apgar score by elective caesarean section.

\section{Congenital heart disease group}

Eight of the nine patients in this group were evaluated during the antenatal period and were all in NYHA class I-II. One had an uncorrected ventriculoseptal defect diagnosed for first time postpartum when she presented in cardiac failure. None had pulmonary hypertension. Six had vaginal delivery, two had an elective caesarian and one had an emergency caesarian. One patient had postpartum haemorrhageTwo babies had complications, namely, birth asphyxia, which responded to resuscitation, and an early neonatal death, respectively. The neonatal death occurred in a mother who had a ventricular septal defect; she went into spontaneous labour at 39 weeks gestation. The progression of labour was uneventful but she delivered an infant with an Apgar score of $3 / 10$.

\section{Group with cardiomyopathy}

This group of nine patients comprised cardiomyopathy , 3 (presented in cardiac failure), hypertensive heart disease 4 , Graves disease and pulmonary embolism. One required intensive-care monitoring post-delivery. She had an ejection fraction of $30 \%$, and required inotropic support with dobutamine. She had a persistent tachycardia that subsided when carvedilol was added to her management. An elective caesarean section was performed and she was managed postoperatively in the ICU with an uneventful recovery. Five were delivered by caesarean section, three had normal vaginal deliveries and one with cardiomyopathy had a miscarriage. One hypertensive patient delivered a pre-term baby.

\section{Outcome of pregnancy}

Since assisted vaginal delivery was construed as the most ideal outcome for both mother and baby, pregnancy outcome was arbitrarily classified in descriptive terms, namely, good, satisfactory and poor; taking into account the mode of delivery and the fetal outcome as follows: good outcome vaginal delivery, no maternal/foetal adverse effects; satisfactory outcome - caesarean section performed with no maternal/fetal adverse effects; and poor outcome - maternal and/or fetal adverse effect, irrespective of mode of delivery. The overall pregnancy outcome was satisfactory (Table 4).

\begin{tabular}{|lccc|}
\hline TABLE 4. PREGNANCY OUTCOME VS CARDIAC LESION \\
& Good & Satisfactory & Poor \\
Metallic valve & 1 & 9 & 10 \\
Mixed mitral valve & 4 & 11 & 2 \\
Mitral stenosis & 6 & 12 & 4 \\
Mitral regurgitation & 7 & 4 & 0 \\
Multi-valve disease & 3 & 3 & 1 \\
Congenital heart disease & 4 & 2 & 3 \\
Myocardial disease & 4 & 3 & 2 \\
\hline
\end{tabular}

In the native valve and prosthetic valve groups, only $21 / 77$ $(27 \%)$ patients had a good outcome, illustrating the significant morbidity associated with these valve lesions.

\section{Mode of delivery}

Fifty-five patients had caesarean : 18 emergencies and 37 elective. In six of 37 patients who had elective, the decision was based purely on the severity of their cardiac disease (Table 5).

\section{Discussion}

As there are so many types of cardiac disease, often with very difficult implications, it is important that a risk assessment of any woman with a heart murmur or a history of any cardiac defect should be carried out early in pregnancy in a joint clinic attended by a consultant obstetrician, cardiologist and anesthetist together called as cardio- obstetrics team (also referred to as the pregnancy heart team).

There was a high rate of complications related to cardiac disease in this study (30\%), the most common being congestive cardiac failure (14\%), followed by arrhythmia $(12 \%)$, and lastly, infective endocarditis (2\%). Eight of the 13 patients with heart failure had valve stenoses and one had an obstructed mitral valve prosthesis. Mitral stenosis was the dominant heart lesion in five patients $(23 \%)$ and prosthetic valve dysfunction was present in two. Non-valvular factors namely, anaemia , urinary tract infection and severe preeclampsia were the precipitating factors for heart failure in these patients.

Atrial fibrillation was present in nine patients (four with metallic valve prosthesis, four with severe mitral stenosis, and one with mixed mitral valve disease). Our five patients with native valve lesions had left atrial sizes ranging from $50-77 \mathrm{~cm}$ and their pulmonary artery systolic pressures ranged from 37-7 $1 \mathrm{mmHg}$. The risk of atrial fibrillation was obviously high in these patients, since they had metallic valves and the hypercoagulable state of pregnancy heightens the risk of valve dysfunction related to clot formation, which dictated the absolute need for adequate and precise anticoagulation.

There was a high adverse event rate in patients with metallic valves. Half of them had complications, all related to the need for effective anticoagulation. However, unsupervised, effective anticoagulation comes with its attendant risk of warfarin embryopathy, spontaneous miscarriages, stillbirths and pre-term deliveries. The incidence of embryopathy varies from $1.8-9.1 \%$. Embryopathy and the stillbirth rate 


\begin{tabular}{|c|c|c|c|c|}
\hline Indication & Elective C/S & Emergency C/S & Severity of cardiac disease & No ofpatients \\
\hline Previous C/S & 6 & 0 & & 6 \\
\hline \begin{tabular}{|l|} 
Twins \\
\end{tabular} & 1 & 0 & & 1 \\
\hline Breech & 2 & 1 & (came in in labour) & 3 \\
\hline $\begin{array}{l}\text { Failed induction of } \\
\text { labour }\end{array}$ & 0 & 4 & $\begin{array}{l}\text { mitral stenosis } 1 \mathrm{ff} \text { balloon mitral valvulopasty / mitral } \\
\text { stenosis } 1.03 \mathrm{ff} \text { balloon mitral valvulopasty / mitral valve } \\
\text { replacement } 32 \text { / congestive cardiac failure, ICU } 0.8 \text { / } \\
\text { mixed mitral valve disease * } 3\end{array}$ & 8 \\
\hline Inadequate pelvis & 6 & 0 & & 6 \\
\hline $\begin{array}{l}\begin{array}{l}\text { Intra-uterine growth } \\
\text { restriction }\end{array} \\
\end{array}$ & 2 & 0 & mitral valve replacement / mitral stenosis 1.6 & 2 \\
\hline $\begin{array}{l}\text { Severe pre- } \\
\text { eclampsia }\end{array}$ & 1 & 1 & & 2 \\
\hline $\begin{array}{l}\text { Obstructive valval } \\
\text { warts }\end{array}$ & 3 & 0 & $\begin{array}{l}\text { mitral valve replacement } 32 \text { / mixed mitral valve } \\
\text { disease }\end{array}$ & 3 \\
\hline $\begin{array}{l}\text { Meconium-stained } \\
\text { liquor }\end{array}$ & 0 & 2 & pre-eclampsia & 2 \\
\hline $\begin{array}{l}\text { Bad obstetric } \\
\text { history }\end{array}$ & 1 & 0 & mixed mitral valve disease & 1 \\
\hline Cardiomyopathy & 1 & 0 & ejection fraction 30 & 1 \\
\hline $\begin{array}{l}\text { Critical/severe } \\
\text { mitral stenosis }\end{array}$ & 2 & 0 & mitral stenosis 0.8/09 & 2 \\
\hline $\begin{array}{l}\text { Severe aortic } \\
\text { stenosis / mitral } \\
\text { stenosis }\end{array}$ & 1 & 0 & 0.9 & 1 \\
\hline $\begin{array}{l}\text { Supraventricular } \\
\text { tachycardia }\end{array}$ & 1 & 0 & aortic regurgitation / mitral regurgitation & 1 \\
\hline $\begin{array}{l}\text { Mitral stenosis / } \\
\text { aortic stenosis }\end{array}$ & 1 & 0 & & 1 \\
\hline $\begin{array}{l}\mathrm{C} / \mathrm{S}=\text { caesarean } \\
\text { section. }\end{array}$ & & & & \\
\hline
\end{tabular}

have been found to be dose dependent, with the incidence increasing in those who require warfarin above $5 \mathrm{mg}$ daily.

The perinatal mortality in our study was increased by the number of stillbirths that occurred in patients with rheumatic heart disease, especially those who were on oral anticoagulants, as well as the poor survival rate in foetuses with congenital malformations. The main factor was difficulty in achieving the target INR level leading to hypercoagulation. In addition, the presentation of these patients late in the second and third trimester did not permit change to heparin in the first trimester and led to the high stillbirth rate. Both foetal and maternal effects of anticoagulant therapy were frequent. Despite these problems, the perinatal mortality rate in this audit was 76/1 000 births, whereas the overall perinatal mortality rate in our unit is 90/1 000 births (department statistics). This was probably achieved by our careful surveillance policy in cardiac patients since we have transferred to the new unit.

There were no maternal deaths in this study. Other studies from resource developing countries document a low but significant maternal mortality rate. Management of anticoagulation in women with mechanical heart valves poses a unique challenge given the risk of valve thrombosis and risk of adverse fetal outcomes. Warfarin is associated with fetal birth defects, and studies have shown this effect may be pronounced when used during weeks 6-12.The fetal risk appears to be dose dependent, with observed fetal risk similar to low molecular weight heparin (LMWH) when the daily dose is $\leq 5 \mathrm{mg}$ of warfarin. Although maternal risk of valve thrombosis is lowest with continued warfarin use throughout all three trimesters of pregnancy, fetal risk is optimized with the use of LMWH or low dose ( $\leq 5 \mathrm{mg}$ daily) of warfarin. Thus, weighing risks and benefits of both maternal and fetal health, warfarin continuation is generally recommended when daily maternal dose is $\leq 5 \mathrm{mg}$ daily, whereas switching to therapeutic LMWH should be considered in patients who require higher warfarin dosing. Low-dose aspirin is recommended in mechanical and bioprosthetic valves in the second and third trimester.When LMWH is used for anticoagulation, meticulous monitoring of anti-Xa levels is required. Anti-Xa levels should be measured 4-6 hours after a dose with a goal range of 0.8-1.2 U/ m. Antico agulation should be discontinued 24 hours prior to the induction of labor or cesarean section. Intravenous unfractionated heparin can then be resumed 6 hours after a vaginal delivery or 12 hours after a cesarean delivery, if adequate hemostasis is achieved.Warfarin may be resumed post-partum and is safe for use during breastfeeding.

Only two patients required cardiac surgery in our study (clotted prosthesis and severe mitral regurgitation). In the past, surgery had a role in symptomatic cases of tight mitral stenosis, but this has now been superseded by BMV, which is effective and safer compared to open mitral valvulotomy and valve replacement.In our study, undetected mitral stenosis resulted in eight patients requiring intervention (BMV) during pregnancy. Recent studies show a decline in the rate of BMVs in pregnancy. Complications of BMV can be quite serious (mortality, cerebrovascular accident, cardiac perforation, mitral regurgitation and atrial septal defect).

The aim of the valvular heart disease classification into stenotic and regurgitant lesions was to define high-risk groups, and it is clear from this review that patients with metallic valves and those who had obstructive lesions .

Another point of note is the seemingly high overall C/S rate in this audit (56\%). In the majority, the indications were purely obstetric, but in six patients it was based on the severity of the cardiac lesion. The high caesarean section rate is a reflection of the high-risk obstetric status of patients managed at this tertiary centre, since the overall caesarean section rate at 
IALCH is $70-80 \%$ ). The indications for caesarean section based on the severity of the disease were taken jointly by cardiologists and obstetricians, taking into account the echocardiographic findings and the clinical status of the patient at the time of decision making.

\section{Conclusion}

Monitoring of anticoagulant therapy in patients with metallic valve prosthesis following valve replacement needs to be improved to minimise fetal loss and maternal bleeding problems most often encountered in these patients. In addition, there was a significant misdiagnosis rate. Clinical assessment remains a prerequisite in identifying symptoms and signs suggestive of cardiac disease, which would determine the need for echocardiographic evaluation. EchoDoppler evaluation by echocardiography accurately diagnosed the nature and severity of cardiac lesions.

\section{REFERENCES}

1. Klein LL, Galan HL. Cardiac disease in pregnancy. Obstet Gynecol Clin NAm 2004;31:429-459.

2. Van Mook WNKA, Peeters L. Severe cardiac disease in pregnancy, part II: impact of congenital and acquired cardiac disease during pregnancy. Curr Opin Crit Care 2005; 11(5):435-448.

3. Anandaraja S, Kothari SS, Bahl VK. Management of valvular heart disease during pregnancy.Ind Heart J2005; 57(2): 101-108.

4. Saving Mothers. A report of the National Committee on Confidential Enquiries into maternal deaths in South Africa (1999-2001) DOH. Pretoria: 162-174.

5. Desai DK, Adanlawo M, Naidoo DP, Moodley J, Kleinschmidt I. Mitral stenosis in pregnancy: a four-year experience at King Edward VIII Hospital, Durban, South Africa. BrJObstet Gynaecol 2000; 107 (8): 953-958.

6. Criteria Committee of the New York Association. Nomenclature and Criteria for Diagnosis of Disease of the Heart and Great Vessels, 6th edn. Boston, MA: Little, Brown, 1964.

7. Bhatla N, Lal S, Behera G, Kriplani A, Mittal S, Agarwal N, et al. Cardiac disease in pregnancy.Int J Gynecol Obstet 2003;82(2): 153-159.

8. Abdel-Hady ES, El-Shamy M, El-Rifai AA, Goda H, AbdelSamad A, Moussa S Maternal and perinatal outcome of pregnancies complicated by cardiac disease.IntJ Gynecol Obstet 2005; 90(1):21-25.

9. Thorne SA.Pregnancy in heart disease. Heart 2004;90:450 456

10. Silversides K, Candice, Colman M, Jack, Sermer M, Siu C, Samuel. Cardiac risk in pregnant women with rheumatic mitral stenosis. Am J Cardiol 2003; 91(11): 1382-1385.

11. J, Rahman MS, Al-Suleiman SA and Al-Jama FE. Pregnancy complicated by maternal cardiac disease: a review of 274 patients. Obstet Gynecol 2000; 20(3):243-245.

12. Malhotra M, Sharma JB, Tripathi R, Arora P, Arora R. Maternal and fetal outcome in valvular heart disease. Int J Gynecol Obstet 2004;84(1): 11-16.

13. Bates S M, Ginsberg J S. Anticoagulants in pregnancy. Bailliere's Clin Obstet Gynaecol 1997; 11(3):479-488.

14. Blickstein D, Blickstein I. The risk of fetal loss associated with warfarin anticoagulation. IntJ Gynecol Obstet 2002; 78(3):221-225.

15. Hung L, Rahimtoola SH. Prosthetic heart valves and pregnancy. Circulation 2003; 107:1240-1246.

16. Hall JG, Pauli RM,Wilson KM. Maternal and fetal sequelae of anticoagulation during pregnancy.AmJMed 1980;68: 122-140.

17. Cotrufo M, De Feo F, De Santos LS, et al. Risk of warfarin during pregnancy with mechanical valve prostheses. Obstet Gynecol 2002;99(1):35-40.

18. Elkayam U, Bitar F. Valvular heart disease and pregnancy part II: Prosthetic valves. JAm Coll Cardiol 2005;46(3):403-410.

19. Bates SM, Greer IA, Hirsh J, Ginsberg JS. Use of antithrombotic agents during pregnancy, the seventh ACCP conference on antithrombotic and thrombolytic therapy. Chest $2004 ; 126: 627 \mathrm{~S}-644 \mathrm{~S}$

20. Reimond C, Sharon, Rutherford DJ. Valvular heart disease in pregnancy. $N$ EnglJMed 2003; 349:52-59

21. Bonow RO, Carabello B, de Leon AC, et al. ACC/AHA guidelines for the management of patients with valvular heart disease: a report of the American College of Cardiology/American Heart Association Task Force on Practice Guidelines (committee on management of patients with valvular heart disease).JAm Coll Cardiol 1998;32:1486-1582.

22. Malhotra M, Sharma JB, Arora P, et al. Mitral valve surgery and maternal and fetal outcome in valvular heart disease. Int J Gynecol Obstet 2003; 81 (2): 151156 .

23. Sawhney H, Aggarwal N, Suri V, Vasishta K, Sharma Y, Grover A. Maternal and perinatal outcome in rheumatic heart disease.Int $J$

24. Siu SC,Sermer M,Colman JM, etal.Prospective multicenter study of pregnancy outcomes in women with heart disease. Circulation 2001;104:51521.

25. Drenthen W, Boersma E, Balci A, et al. Predictors of pregnancy complications in women with congenital heart disease. Eur HeartJ2010;31:2124-32.

26. Barbour LA. Current concepts of anticoagulant therapy in pregnancy. Obstet Gynecol Clin NorthAm 1997;24:499-521.

27. Elkayam U, Goland S, Pieper PG, Silverside CK. High-risk cardiac disease in pregnancy: part I.J Am Coll Cardiol. 2016; 68:396-410. doi: pregnancy: part 1.J A

28. Thorne S, MacGregor A, Nelson-Piercy C. Risks of contraception and pregnancy in heart disease.Heart. 2006; 92:1520-1525. doi: 10.1136/hrt.2006.095240

29. Thorne S. Risks of contraception and pregnancy in heart disease.Heart. 2006; 92:1520-1525 